types for teaching and experiment. Mr. H. R. Hewer, secretary of the Association, read the report of this committee. A list of the names accepted at present as correct for a large number of animals has been prepared, and it is hoped to publish this list in the near future. Prof. J. W. Munro, of the Imperial College of Science, opened a discussion on the extent of the opportunities which are at present available to junior members of the staffs of the universities for carrying on individual research. Dr. B. Dawes, Mr. C. C. Hentschell, Dr. E. B. Worthington and others spoke on this subject. It was the general view that, so long as promotion in the universities is made to depend, as it so often is at present, on the results of research, the members of the staffs should be given more opportunities for carrying out this research. Either increase in the number of the staffs, or provision of research grants for members of the teaching staff by which they could be released from teaching duties in whole or in part for short periods, would ease the position. A third discussion was held on the conditions under which consultant work in zoology is being carried on. Such work has considerably increased in recent years in spite of the existence of several institutions provided by the Government for the study of problems in economic zoology. Dr. J. C. F. Fryer of the Ministry of Agriculture, Dr. R. C. Fisher of the Forest Products Research Laboratory, Princes Risborough, and Mr. H. R. Hewer spoke in this discussion, and the Council of the Association was asked to make inquiries whether it would be possible to prepare a list of recognised zoologists qualified to give advice on these matters.

\section{Science and Values}

IN his retiring presidential address to the American Association for the Advancement of Science delivered at St. Louis on December 30, Prof. E. L. Thorndike, under the title "Science and Values", discussed the psychology of values in its relation to the competence of science to improve the judgments of value and esteem which rule men, and the possible contribution of scientific methods in the treatment of moral questions. Pointing out that the discussion of questions of value by philosophic thinkers has made little advance since the time of Aristotle in spite of the general advance of knowledge, Prof. Thorndike asserted that judgments of value or worth are simply a special sort of judgments of fact or existence, distinguished by being concerned with consequences, and with consequences to the wants of sentient beings. Values, positive or negative, reside in the satisfaction or annoyance felt by animals, persons or deities, and while competent students judge the existence of things by observations, they judge the values of things by observations of their consequences. Creating and enjoying truth or beauty are examples of the class of satisfiers which involve positive satisfaction for some without subtraction from, and often with addition to, those of others. Where satisfactions and annoyances lie within the natural world of men or animals, they are amenable to scientific study.
Sometimes indeed it is necessary to judge the value of things, events and relations indirectly by their affiliations, for which a special technique is required.

Asthough, therefore, values are difficult to determine, they are not banished entirely from the realm of science but are amenable to scientific methods. The work of a science of values, a realistic ethics, is to learn what men do want and how to improve their wants, and to trace the consequences of acts, events, ideas, attitudes, etc. So far, science has tended to leave values alone; but it is not wise to leave decisions about consequences entirely to the humanists. We should regard nothing as outside the scope of science, and every regularity or law that science can discover in the consequences of events is a step towards the only freedom that is of use to man and an aid in the good life. If values do not reside in the orderly world of Nature but depend on chance and caprice, it would be in vain to try to increase them. The world needs not only the vision and valuation of great sages, and the practical psychology of men of affairs, but also scientific methods to test the worth of the prophets' dreams, and scientific humanists to inform and advise its men of affairs, not only about what is, but also about what is right and good.

\section{New Type of Aircraft Structure}

Messrs. Vickers (Aviatron) Ltd, have commenced work upon a production order of 'Wellesley' military aeroplanes, introducing a type of construction with an estimated saving of $35-40$ per cent in structure weight, which can be used for increasing either useful carrying capacity or extra fuel, giving greater range. It is known as the 'geodetic' principle, and has been developed by Mr. B. N. Wallis, from a similar method used by him in the construction of the British airship R.100. The general principle is that the stresses in the structure are taken by a skin which follows a path between any two points taken by the surface of a cylinder or sphere. The skin is built up by a large number of small members, placed criss-cross, disposed of in such a way, and of the correct size, to take the local loading most advantageously. Thus the advantage of a skin construction, in that the interior of the wing or body is left clear, is obtained, with the added gain that local damage, as from gun fire, is confined to the actual parts broken, and does not spread catastrophically, as in the case of a very thin continuous skin. Stressed skin construction has many advantages. The higher loading with increased speeds can be taken with a proportionately smaller increase in weight than with the more conventional structures. The absence of interior bracing simplifies the questions of storage of the carried load. The problem of producing a wing of variable area to suit varying flight conditions becomes feasible, by making the outer wing portions telescopic, which is almost an impossibility with an interior stressed struo. ture. 